\title{
Hydrogen Sulfide, a Toxic Gas with Cardiovascular Properties in Uremia: How Harmful Is It?
}

\author{
Alessandra F. Perna ${ }^{a}$ Diana Lanza ${ }^{a} \quad$ Immacolata Sepe ${ }^{a} \quad$ Ilaria Raiola $^{a}$ \\ Rosanna Capasso $^{b}$ Natale G. De Santo ${ }^{a}$ Diego Ingrosso ${ }^{b}$ \\ ${ }^{a}$ First Division of Nephrology, Department of Clinical and Experimental Internal Medicine, and \\ ${ }^{b}$ Department of Biochemistry and Biophysics 'F. Cedrangolo', Second University of Medicine, Naples, Italy
}

\section{Key Words}

Cystathionine $\gamma$-lyase $\cdot$ Hemodialysis $\cdot$ Hydrogen sulfide .

Hypertension • Diabetes

\begin{abstract}
Hydrogen sulfide $\left(\mathrm{H}_{2} \mathrm{~S}\right)$ is a poisonous gas which can be lethal. However, it is also produced endogenously, thus belonging to the family of gasotransmitters along with nitric oxide and carbon monoxide. $\mathrm{H}_{2} \mathrm{~S}$ is in fact involved in mediating several signaling and cytoprotective functions, for example in the nervous, cardiovascular, and gastrointestinal systems, such as neuronal transmission, blood pressure regulation and insulin release, among others. When increased, it can mediate inflammation and apoptosis, with a role in shock. When decreased, it can be involved in atherosclerosis, hypertension, myocardial infarction, diabetes, sexual dysfunction, and gastric ulcer; it notably interacts with the other gaseous mediators. Cystathionine $\gamma$-lyase, cystathionine $\beta$ synthase, and 3-mercaptopyruvate sulfurtransferase are the principal enzymes involved in $\mathrm{H}_{2} \mathrm{~S}$ production. We have recently studied $\mathrm{H}_{2} \mathrm{~S}$ metabolism in the plasma of chronic hemodialysis patients and reported that its levels are significantly decreased. The plausible mechanism lies in the transcription inhibition of the cystathionine $\gamma$-lyase gene. The
\end{abstract}

finding could be of importance considering that hypertension and high cardiovascular mortality are characteristic in these patients.

Copyright $\odot 2011$ S. Karger AG, Basel

\section{Introduction}

Hydrogen sulfide $\left(\mathrm{H}_{2} \mathrm{~S}\right)$ is a poisonous and occasionally lethal gas. It is formed in the decomposition of any organic material and represents an industrial occupational safety hazard. Known for its typical stench of rotten eggs, it is now being largely reconsidered relatively to this 'bad guy' role. In fact, it is recognized that the body not only can tolerate this gas in very small amounts, but produces $\mathrm{H}_{2} \mathrm{~S}$ in a variety of tightly regulated pathways [1-5].

\section{$\mathrm{H}_{2} \mathrm{~S}$ Formation}

It is now believed that $\mathrm{H}_{2} \mathrm{~S}$ formation (fig. 1) is catalyzed by three enzymes (but nothing hinders that more may be revealed as research grows on the subject; for example, some pharmacological inhibitors of its production 


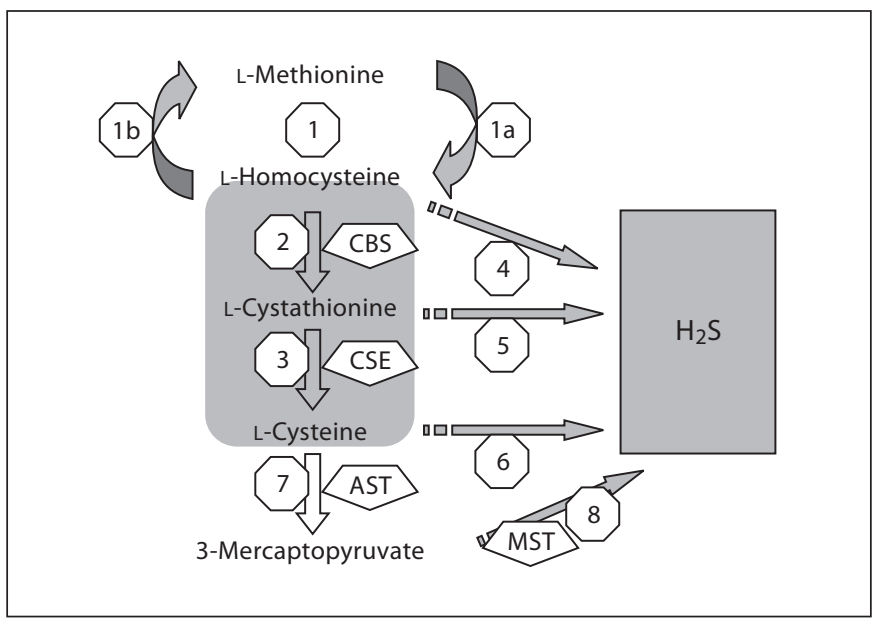

Fig. 1. Metabolism of sulfur amino acids relevant to $\mathrm{H}_{2} \mathrm{~S}$ production. L-methionine, an essential amino acid, can be converted to L-homocysteine through the methionine-homocysteine cycle (step 1), schematically represented by curved arrows. Step 1a: conversion of methionine into $S$-adenosyl-L-methionine and its demethylation through the action of various methyltransferases, leading to the formation of $S$-adenosyl-L-homocysteine, the direct homocysteine precursor. Step 1b: conversion of homocysteine back to methionine. Reaction $1 b$ is catalyzed by methionine synthase (requiring methyl cobalamine as a coenzyme and N5-methyltetrahydrofolate as a cosubstrate). L-homocysteine is also quantitatively converted into L-cysteine through a two-reaction pathway (transsulfuration; grey area), including step 2 (catalyzed by the rate-limiting CBS) and step 3 (catalyzed by CSE). Vitamin $\mathrm{B}_{6}$ is required for CBS and CSE activity through its cofactor pyridoxal phosphate. Both CBS and CSE can lead to the formation of $\mathrm{H}_{2} \mathrm{~S}$ as a side product, CSE being a major $\mathrm{H}_{2} \mathrm{~S}$ producer. Both Lhomocysteine (step 4) and L-cysteine (step 6) can act as $\mathrm{H}_{2} \mathrm{~S}$ precursors, as well as cystathionine (step 5) [for details see reference 32]. A minor pathway for $\mathrm{H}_{2} \mathrm{~S}$ production includes the sequential action of aspartate aminotransferase (AST; step 7) and MST (step 8) [see also reference 33].

do not appear to exert hemodynamic effects in normal animals if given acutely): cystathionine $\gamma$-lyase (CSE; cystathionase, EC 4.4.1.1), cystathionine $\beta$-synthase (CBS; EC 4.2.1.22), and 3-mercaptopyruvate sulfurtransferase (MST; EC 2.8.1.2). In the vascular system, $\mathrm{H}_{2} \mathrm{~S}$ is synthesized by CSE in vascular smooth muscle cells and endothelial cells, while in the brain its production is attributed to CBS. In the kidney, all three enzymes are active [6-9], with studies suggesting that $\mathrm{H}_{2} \mathrm{~S}$ is involved in the control of renal function.

CSE in the transsulfuration pathway catalyzes the conversion of cystathionine to cysteine. It also catalyzes $\mathrm{H}_{2} \mathrm{~S}$ formation in a reaction utilizing cystine, a cysteine oxidation product, producing pyruvate, ammonia and thiocysteine, which in turn forms cysteine and $\mathrm{H}_{2} \mathrm{~S}$. CBS catalyzes the formation of cystathionine and water by condensing serine and homocysteine, a key irreversible reaction in the transsulfuration pathway. Homocysteine lies at a crucial metabolic branch point between transsulfuration and the methionine-homocysteine cycle. It has been also demonstrated that CBS can, in an alternate reaction, catalyze the formation of cystathionine and $\mathrm{H}_{2} \mathrm{~S}$ through condensation of cysteine and homocysteine as substrates [10]. Vitamin $\mathrm{B}_{6}$ is required for CBS and CSE activity through its cofactor pyridoxal phosphate. MST catalyzes the formation of $\mathrm{H}_{2} \mathrm{~S}$ from 3-mercaptopyruvate, a cysteine metabolite, or it can transfer its sulfur atom to sulfite, which forms thiosulfate. Cysteine formed by CSE can then act as an acceptor of the sulfur transferred from 3-mercaptopyruvate by MST [11].

In addition, $\mathrm{H}_{2} \mathrm{~S}$ is formed nonenzymatically from elemental sulfur, inorganic polysulfides and organic polysulfides, contained for example in garlic. Therefore, garlic's apparent health benefits may be related to $\mathrm{H}_{2} \mathrm{~S}$ [12]. Garlic extracts are effective for example in slowing the progression of subclinical atherosclerosis, due to $\mathrm{H}_{2} \mathrm{~S}$ generation from S-allylcysteine and S-allylmercaptocysteine [13].

\section{$\mathrm{H}_{2} \mathrm{~S}$ Properties}

$\mathrm{H}_{2} \mathrm{~S}$ is a weak acid, more soluble in lipophilic solvents than in water. There are no known membrane receptors: $\mathrm{H}_{2} \mathrm{~S}$ seems to cross membranes through simple diffusion. In aqueous solution, it exists in the equilibrium: $\mathrm{H}_{2} \mathrm{~S}$ $\leftrightarrows \mathrm{HS}^{-}+\mathrm{H}^{+} \leftrightarrows \mathrm{S}^{2-}+2 \mathrm{H}^{+}$. In plasma and in the extracellular fluid, $\mathrm{H}_{2} \mathrm{~S}$ is present in its undissociated acid form, in less than $20 \%$, and about $80 \%$ as the hydrosulfide anion HS$^{-}$. The undissociated form $\mathrm{H}_{2} \mathrm{~S}$ is volatile, while $\mathrm{HS}^{-}$is not.

\section{Biological Effects}

$\mathrm{H}_{2} \mathrm{~S}$ is entitled to belong to the gasotransmitter family, along with nitric oxide (NO) and carbon monoxide (CO). In fact, $\mathrm{H}_{2} \mathrm{~S}$ exerts cardioprotective actions in several models of cardiac injury, such as ischemia/reperfusion injury and heart failure, and plays a role in pulmonary hypertension induced by hypoxia. $\mathrm{H}_{2} \mathrm{~S}$ is able to reduce blood pressure in rats, and to induce vasodilation of isolated blood vessels. Low $\mathrm{H}_{2} \mathrm{~S}$ generation has been demonstrated in the vasculature of spontaneously hypertensive rats, and chronic administration of a CSE inhibitor in- 
duces arterial hypertension. Its actions are mediated by the opening of potassium ATP-dependent channels in vascular smooth muscle cells, independently of membrane receptors, and partially through $\mathrm{K}^{+}$conductance in endothelial cells. $\mathrm{H}_{2} \mathrm{~S}$ is produced by vascular smooth muscle cells, and by endothelial cells through CSE. Importantly, Yang et al. [14] demonstrated that in CSE knockout mice, $\mathrm{H}_{2} \mathrm{~S}$ is markedly reduced in serum and many tissues; pronounced age-dependent hypertension and reduced endothelium-dependent vasorelaxation are present. Mutant mice display hyperhomocysteinemia and low cysteine levels, as expected as a consequence of their metabolic block. $\mathrm{H}_{2} \mathrm{~S}$ is consistently reduced in plasma and tissues [14]. An observational study in coronary heart disease patients, hypertensives, and smokers, has also shown that plasma $\mathrm{H}_{2} \mathrm{~S}$ is lower compared to normal subjects. Low $\mathrm{H}_{2} \mathrm{~S}$ was found in hypertensive children as well [see 15 for review on this topic]. In this respect, it has recently been shown that $\mathrm{H}_{2} \mathrm{~S}$ inhibits plasma renin activity by decreasing synthesis and release of renin in a rat model of renovascular hypertension [16].

In addition, $\mathrm{H}_{2} \mathrm{~S}$ exerts antiatherosclerotic effects, for example in apolipoprotein $\mathrm{E}$ knockout mice [17]. In these mice, treatment with $\mathrm{NaHS}$, an $\mathrm{H}_{2} \mathrm{~S}$ donor, is able to reduce plaque size, which is probably mediated by reduced intracellular adhesion molecule- 1 in circulation and in endothelial cells. $\mathrm{H}_{2} \mathrm{~S}$ deficiency could be also involved in sexual dysfunction [18].

It has been shown by Wu et al. [19] that this gas could be important in the pathogenesis of diabetes mellitus; in fact, it is produced in $\beta$-cells. In animals with type 1 diabetes, streptozotocin-induced $\mathrm{H}_{2} \mathrm{~S}$ production is increased; the authors argue that this excess implies two consequences: one the one hand, it destroys a great number of $\beta$-cells, leaving in site too few cells to deal with the necessities of the body. On the other hand, it inhibits insulin release from the remaining cells. Other authors [20, 21] show instead that this is a biphasic effect, in the sense that at low concentrations insulin release is inhibited through a $\mathrm{K}_{\mathrm{ATP}}$-dependent $/ \mathrm{Ca}^{2+}$-independent mechanism, while higher levels induce $\beta$-cell death through a pathway dependent on endoplasmic reticulum stress. Similarly, in nonobese diabetic mice, $\mathrm{H}_{2} \mathrm{~S}$ levels and the response of vascular tissue to endothelium-dependent vasodilators, such as acetylcholine, are reduced, and aortic $\mathrm{H}_{2} \mathrm{~S}$ synthesis is progressively reduced with the progression of diabetic disease [22]. In type 2 diabetes patients, plasma $\mathrm{H}_{2} \mathrm{~S}$ levels are significantly reduced, with respect to lean control patients. In the latter study, adiposity revealed itself as an important determinant of $\mathrm{H}_{2} \mathrm{~S}$ levels [23]. In this context, it is relevant that in uninephrectomized mice, characterized by CBS deficiency, proteinuria and kidney function indexes get significantly worse when compared to wild-type mice [24]. In addition, the chronic administration of propargylglycine, a CSE inhibitor, induces nephropathy. Jain et al. [25] have recently shown that $\mathrm{H}_{2} \mathrm{~S}$ is lower in the blood of type 2 diabetic patients, confirming the data by Whiteman et al. [23], and that in human monocytes treated with glucose, $\mathrm{H}_{2} \mathrm{~S}$ or cysteine supplementation prevents interleukin-8 and monocyte chemoattractant protein-1 secretion [25]. In addition, it is interesting to note that cysteine administration inhibits insulin release by pancreatic $\beta$-cells [26].

Aside from cardiovascular and metabolic effects, $\mathrm{H}_{2} \mathrm{~S}$ has been shown to act as a neuromodulator, agonist of the $\mathrm{N}$-methyl-D-aspartate receptor at the cerebral level. $\mathrm{H}_{2} \mathrm{~S}$ is also involved in inflammation, apoptosis, and antioxidation [for review see 1-5]; it may influence longevity, and it is possible that it can be employed in eliciting suspended animation, therefore finding a role in transplantation and space travel. Indeed, it is difficult to find, like its gaseous companions $\mathrm{NO}$ and $\mathrm{CO}$, a molecule with more pleiotropic properties.

\section{Mechanisms of Action}

The mechanisms through which $\mathrm{H}_{2} \mathrm{~S}$ acts on the various systems and functions are direct or through its $\mathrm{HS}^{-}$ form. It is also entirely possible that all the main effects of $\mathrm{H}_{2} \mathrm{~S}$ are due to protein $\mathrm{S}$-sulfhydration, mediated through HS', which occurs at the level of cysteine residues, leading to the formation of persulfides (-SSH groups) [27]. In fact, the sulfhydration of glyceraldehyde3-phosphate dehydrogenase, among other proteins, is able to dramatically improve its activity. Also, $\mathrm{H}_{2} \mathrm{~S}$ enhances actin polymerization [27].

\section{$\mathrm{H}_{2} \mathrm{~S}$ in Hemodialysis Patients}

Chronic kidney disease (CKD), especially in its terminal stage, is characterized by high cardiovascular mortality. While in the general population cardiovascular risk decreased steadily in the last few decades, this did not happen in these patients. More reliable biomarkers for predicting cardiovascular risk in CKD patients are under investigation. Thiol metabolites, such as homocysteine, cysteine, and S-adenosylhomocysteine, are increased in 
CKD patients, reaching their highest levels in hemodialysis patients [28]. Homocysteine and cysteine, or their direct derivatives, are utilized as substrates by the key enzymes involved in $\mathrm{H}_{2} \mathrm{~S}$ biosynthesis, namely, CBS, CSE, and MST.

Contrary to the expectation, however, $\mathrm{H}_{2} \mathrm{~S}$ is decreased in the plasma of hemodialysis patients [29]. We have in fact shown that not only $\mathrm{H}_{2} \mathrm{~S}$ is lower, but also red cell sulfhemoglobin (a putative marker of chronic $\mathrm{H}_{2} \mathrm{~S}$ exposure), while high plasma homocysteine and cysteine are present, with a significant negative correlation between cysteine and $\mathrm{H}_{2} \mathrm{~S}$. The cofactor of CBS and CSE, vitamin $\mathrm{B}_{6}$, is not different in patients with respect to controls. The methylenetetrahydrofolate reductase gene polymorphism does not influence $\mathrm{H}_{2} \mathrm{~S}$ blood levels. Gene expression of CBS, CSE and MST was measured in nucleated blood cells. Expression of CBS was not present in blood, while that of CSE is significantly lower [29].

In light of these findings, it can be hypothesized that the mechanism of hyperhomocysteinemia in uremia, an issue still not resolved, could find a plausible explanation in this genetic derangement in CSE function. As seen in the CSE knockout mice, where CSE function is not present, hyperhomocysteinemia is part of the picture. In addition to this, the lower $\mathrm{H}_{2} \mathrm{~S}$ production can be explained by CSE gene downregulation.

MST expression was found to be significantly increased. MST is mainly devoted to the detoxification of cyanide, which is transformed into thiocyanate. Interest- ingly, cyanide and thiocyanide levels are higher in blood of hemodialysis patients [29]. We can therefore speculate that this enzyme's gene expression is increased because of the necessity to dispose of excess plasma cyanide, typical of these patients. However, since CSE is quantitatively more important in $\mathrm{H}_{2} \mathrm{~S}$ production, the end result is lower blood $\mathrm{H}_{2} \mathrm{~S}$ in these patients. Interestingly, in a model of uninephrectomized hyperhomocysteinemic mice, $\mathrm{H}_{2} \mathrm{~S}$ is reduced in blood, and $\mathrm{H}_{2} \mathrm{~S}$ supplementation prevents the hyperhomocysteinemia-associated renal damage [24].

In conclusion, $\mathrm{H}_{2} \mathrm{~S}$ deficiency due to reduced gene expression of CSE can be considered one of the manifold manifestations of the uremic toxicity syndrome, and can in turn cause some of its characteristics. However, it is not to be expected that such a complex disease condition could be easily represented, for what related to deranged vascular homeostasis, by a relatively simple model, i.e. using inhibitors of $\mathrm{H}_{2} \mathrm{~S}$-producing enzymes (particularly CSE) to mimic the molecular scenario underlying the generation of hypertension in chronic uremia. Nevertheless, a better knowledge of $\mathrm{H}_{2} \mathrm{~S}$ and its functions in this patient population could have high therapeutic value [30, 31]. This is especially true if we consider that $\mathrm{H}_{2} \mathrm{~S}$ may indeed regulate blood pressure through its interactions with $\mathrm{NO}$ [30], and in disease states such as the one we are evaluating, it may regulate vascular tone also in more subtle ways [30].

\section{References}

1 Gadalla MM, Snyder SH: Hydrogen sulfide as a gasotransmitter. J Neurochem DOI: 10.1111/j.1471-4159.2010.06580.x.

2 Kimura H: Hydrogen sulfide: its production, release and functions. Amino Acids DOI: 10.1007/s00726-010-0510-x

-3 Lefer DJ: A new gaseous signaling molecule emerges: cardioprotective role of hydrogen sulfide. Proc Natl Acad Sci USA 2007;104: 17907-17908.

4 Szabo C: Hydrogen sulphide and its therapeutic potential. Nat Rev 2007;6:917-935.

5 Li L, Moore PK: Putative biological roles of hydrogen sulfide in health and disease: a breath of not so fresh air? Trends Pharmacol Sci 2008;29:84-90.

-6 Tripatara P, Patel NSA, Collino M, Gallicchio M, Kieswich J, Castiglia S, Benedetti E, Stewart KN, Brown PAJ, Yaqoob MM, Fantozzi R, Thiemermann C: Generation of endogenous hydrogen sulfide by cystathionine $\gamma$-lyase limits renal ischemia/reperfusion in- jury and dysfunction. Lab Invest 2008;88: 1038-1048.

7 Xia M, Chen L, Muh RW, Li PL, Li N: Production and actions of hydrogen sulfide, a novel gaseous bioactive substance, in the kidneys. J Pharmacol Exp Ther 2009;329:1056-1062.

$8 \mathrm{Wu}$ N, Siow YL, Karmin O: Ischemia/reperfusion reduces transcription factor SP1 mediated cystathionine beta-synthase expression in the kidney. J Biol Chem DOI: 10.1074/ jbc.M110.132142.

9 Beltowski J: Hypoxia in the renal medulla: implications for hydrogen sulfide signaling. J Pharmacol Exp Ther DOI: 10.1124/ ipet.110.166637.

10 Chen X, Jhee K, Kruger WD: Production of the neuromodulator $\mathrm{H}_{2} \mathrm{~S}$ by cystathionine $\beta$ synthase via the condensation of cysteine and homocysteine. J Biol Chem 2004;279: 52082-52086.

11 Shibuya N, Mikami Y, Kimura Y, Nagahara $\mathrm{N}$, Kimura H: Vascular endothelium ex- presses 3-mercaptopyruvate sulfurtransferase and produces hydrogen sulfide. J Biochem 2009; 146:623-626.

12 Benavides GA, Squadrito GL, Mills RW, Patel HD, Isbell TS, Patel RP, Darley-Usmar VM, Doeller JE, Kraus DW: Hydrogen sulfide mediates the vasoactivity of garlic. Proc Natl Acad Sci USA 2007;104:17977-17982.

$>13$ Budoff MJ, Ahmadi N, Gul KM, Liu ST, Flores FR, Tiano J, Takasu J, Miller E, Tsimikas S: Aged garlic extract supplemented with $B$ vitamins, folic acid and L-arginine retards the progression of subclinical atherosclerosis: a randomized clinical trial. Prev Med 2009;49:101-107.

14 Yang G, Wu L, Jiang B, Yang W, Qi J, Cao K, Meng Q, Mustafa AK, Mu W, Zhang S, Snyder $\mathrm{SH}$, and Wang $\mathrm{R}: \mathrm{H}_{2} \mathrm{~S}$ as a physiologic vasorelaxant: hypertension in mice with deletion of cystathionine gamma-lyase. Science 2008;322:587-590. 
-15 Perna AF, Luciano MG, Ingrosso D, Raiola I, Pulzella P, Sepe I, Lanza D, Violetti E, Capasso R, Lombardi C, De Santo NG: Hydrogen sulfide, the third gaseous signaling molecule with cardiovascular properties, is decreased in hemodialysis patients. J Ren Nutr 2010;20(suppl):S11-S14.

-16 Lu M, Liu Y, Goh HS, Wang JJ, Yong QC, Wang R, Bian JS: Hydrogen sulfide inhibits plasma renin activity. J Am Soc Nephrol 2010;21:993-1002.

17 Wang Y, Zhao X, Jin H, Wei H, Li W, Bu D, Tang X, Ren Y, Tang X, Du J: Role of hydrogen sulfide in the development of atherosclerotic lesions in apolipoprotein E knockout mice. Arterioscler Thromb Vasc Biol 2008; 29:173-179.

-18 D’Emanuele di Villa Bianca R, Sorrentino R, Maffia P, Mirone V, Imbimbo C, Fusco F, De Palma R, Ignarro LJ, Cirino G: Hydrogen sulfide as a mediator of human corpus cavernosum smooth-muscle relaxation. Proc Natl Acad Sci USA 2009; 106:4513-4518.

-19 Wu L, Yang W, Jia X, Yang G, Duridanova D, Cao K, Wang R: Pancreatic islet overproduction of $\mathrm{H} 2 \mathrm{~S}$ and suppressed insulin release in Zucker diabetic rats. Lab Invest 2009;89:5967.

20 Ali MY, Whiteman M, Low CM, Moore PK: Hydrogen sulphide reduces insulin secretion from HIT-T15 cells by a KATP channel-dependent pathway. J Endocrinol 2007;195: 1205-1212.
21 Yang G, Yang W, Wu L, Wang R: H2S, endoplasmic reticulum stress, and apoptosis of insulin-secreting beta cells. J Biol Chem 2007;292:16567-16576.

22 Brancaleone V, Roviezzo F, Velleco V, De Gruttola L, Bucci M, Cirino G: Biosynthesis of $\mathrm{H} 2 \mathrm{~S}$ is impaired in non-obese diabetic (NOD) mice. Br J Pharmacol 2008;155:673680 .

23 Whiteman M, Gooding KM, Whatmore JL, Ball CI, Mawson D, Skinner K, Tooke JE, Shore AC: Adiposity is a major determinant of plasma levels of the novel vasodilator hydrogen sulfide. Diabetologia 2010;53:17221726.

24 Sen U, Basu P, Abe OA, Givvimani S, Tyagi N, Metreveli N, Shah KS, Passmore JC, Tyagi SC: Hydrogen sulfide ameliorates hyperhomocysteinemia-associated chronic renal failure. Am J Physiol Ren Physiol 2009; 297:F410-F419.

25 Jain SK, Bull R, Rains JL, Bass PF, Levine SN, Reddy S, McVie R, Bocchini JA: Low levels of hydrogen sulfide in the blood of diabetes patients and streptozotocin-treated rats causes vascular inflammation? Antioxid Redox Signal 2010;12:1333-1337.

26 Kaneko Y, Kimura Y, Kimura H, Niki I: Lcysteine inhibits insulin release from the pancreatic beta-cell: possible involvement of metabolic production of hydrogen sulfide, a novel gasotransmitter. Diabetes 2006;55: 1391-1397.

27 Mustafa AK, Gadalla MM, Sen N, Kim S, Mu W, Gazi SK, Barrow RK, Yang G, Wang R, Snyder $\mathrm{SH}: \mathrm{H}_{2} \mathrm{~S}$ signals through protein $\mathrm{S}$ sulfhydration. Sci Signal 2009;2:ra72.
28 Perna AF, Ingrosso D, Violetti E, Luciano MG, Sepe I, Lanza D, Capasso R, Ascione E, Raiola I, Lombardi C, Stenvinkel P, Massy Z, De Santo NG: Hyperhomocysteinemia in uremia - a red flag in a disrupted circuit. Semin Dial 2009;22:351-356.

$>29$ Perna AF, Luciano MG, Ingrosso D, Pulzella P, Sepe I, Lanza D, Violetti E, Capasso R, Lombardi C, De Santo NG: Hydrogen sulphide-generating pathways in haemodialysis patients: a study on relevant metabolites and transcriptional regulation of genes encoding for key enzymes. Nephrol Dial Transplant 2009;24:3756-3763.

30 Elsey DJ, Fowkes RC, Baxter GF: Regulation of cardiovascular cell function by hydrogen sulfide $\left(\mathrm{H}_{2} \mathrm{~S}\right)$. Cell Biochem Funct DOI: $10.1002 / \mathrm{cbf} .1618$.

-31 Bos EM, Leuvenink HGD, Snijder PM, Kloosterhuis NJ, Hillebrands J, Leemans JC, Florquin S, van Goor H: Hydrogen sulfideinduced hypometabolism prevents renal ischemia/reperfusion injury. J Am Soc Nephrol 2009;20:1901-1905.

-32 Chiku T, Dominique Padovani D, Zhu W, Singh S, Vitvitsky V, Banerjee $\mathrm{R}: \mathrm{H}_{2} \mathrm{~S}$ biogenesis by human cystathionine $\gamma$-lyase leads to the novel sulfur metabolites lanthionine and homolanthionine and is responsive to the grade of hyperhomocysteinemia. J Biol Chem 2009;284:11601-11612.

33 Mancardi D, Penna C, Merlino A, Del Soldato P, Wink DA, Pagliaro P: Physiological and pharmacological features of the novel gasotransmitter: hydrogen sulfide. Biochim Biophys Acta 2009;1787:864-872. 